\title{
Brain shrinkage in alcoholics is not caused by changes in hydration: a pathological study
}

\author{
CLIVE G HARPER, ${ }^{*} \dagger$ JILLIAN J KRIL, ${ }^{*}$ JOHN M DALY
}

From the Department of Pathology, The University of Sydney, ${ }^{*}$ Sydney; Department of Anatomical Pathology, Royal Prince Alfred Hospital, $\ddagger$ Camperdown, NSW; Department of Neuropathology, Royal Perth Hospital, $\uparrow$ Perth WA, Australia

SUMMARY Measurement of the water content of the cerebral white matter in 26 control and 24 alcoholic cases supports in vivo MRI studies and previous necropsy studies which appeared to show an increase in the water content in the alcoholic group. This negates the hypothesis that reversible brain shrinkage in alcoholics is caused by changes in the state of hydration.

Shrinkage of the brain in chronic alcoholic patients has been well documented. ${ }^{2}$ Reversibility of this shrinkage has also been noted in a proportion of alcoholics $^{3}$ and heavy social drinkers ${ }^{4}$ following prolonged abstinence from alcohol. The pathogenesis of these brain volume changes has yet to be elucidated. A number of mechanisms have been suggested, the most obvious being a change in the hydration of the brain tissue. Such an hypothesis is supported by reports of altered body water balance in relation to the ingestion of alcohol and during the withdrawal phase in alcoholics. ${ }^{5}$ It should, however, be noted that reversibility of brain shrinkage occurs over a period of weeks to months rather than days. This implies some structural change rather than a change in the state of hydration of the brain tissue.

Quantitative neuropathological studies by the authors have established that chronic alcoholic subjects have brain shrinkage. ${ }^{267}$ Moreover, quantitation of the volumes of cortical grey matter, white matter and basal ganglia in the brains of control and alcoholic subjects has shown that the loss of cerebral tissue in alcoholics is largely from the white matter. ${ }^{8}$

The purpose of this study was to examine the hypothesis that brain shrinkage and a reduction in the

Address for reprint requests: Professor C G Harper, Department of Pathology, The University of Sydney, Sydney, NSW 2006, Australia

Received 2 June 1987 and in revised form 23 July 1987. Accepted 4 August 1987 white matter volume in alcoholic patients is caused by alterations in the state of hydration.

\section{Subjects and materials}

Cases were selected from the Perth City Coroner's Department. There were 26 control and 24 alcoholic subjects. All subjects were male and Caucasian. The selection of "control" and "alcoholic" cases was made on a compilation of clinical and pathological data. These data included clinical notes from the teaching hospitals of Perth as a result of previous admissions, detailed questionnaires on the alcoholic intake, provided by the relatives of the subjects and a complete necropsy with microscopic examination of tissues including the liver and brain. Patients with a history or pathological evidence of a neurological disease, other than those associated with alcoholism, were excluded as were any patients with evidence of head injury.

Included in the alcoholic group were seven cases of Wernicke's encephalopathy, which is caused by vitamin $B_{1}$ deficiency. These cases were included because the patients had a strong history of alcoholic abuse and previous studies have shown that Wernicke's encephalopathy is closely associated with alcoholism. ${ }^{9}$ Nine cases had cirrhosis of the liver. None of the cases had histological evidence of hepatic encephalopathy. Subgroups of those cases with either Wernicke's encephalopathy or cirrhosis were selected from the alcoholics and the results for these subgroups compared with the controls. Three cases had both Wernicke's encephalopathy and cirrhosis and these were not included in the subgroups. With regard to the alcohol intake of the control cases four were teetotal and the others drank less than 20 grams of ethanol per day. 
Table 1 Age,postmortem interval, brain weight and PICS data for the control and alcoholic groups

\begin{tabular}{|c|c|c|c|c|c|c|c|c|c|}
\hline \multirow[b]{2}{*}{ Group } & \multirow[b]{2}{*}{$n$} & \multicolumn{2}{|l|}{ Age } & \multicolumn{2}{|c|}{ Hours PM } & \multicolumn{2}{|c|}{ Brain weight } & \multicolumn{2}{|c|}{$P I C S^{*}$} \\
\hline & & $\begin{array}{l}\text { Mean } \\
(y r)\end{array}$ & $\overline{(S E M)}$ & $\begin{array}{l}\text { Mean } \\
(h)\end{array}$ & $\overline{(S E M)}$ & $\begin{array}{l}\text { Mean } \\
(g)\end{array}$ & $\overline{(S E M)}$ & $\begin{array}{l}\text { Mean } \\
(\%)\end{array}$ & $(S E M)$ \\
\hline $\begin{array}{l}\text { Control } \\
\text { Alcoholic } \\
\text { Alco + WE } \\
\text { Alco + cir }\end{array}$ & $\begin{array}{r}26 \\
24 \\
4 \\
6\end{array}$ & $\begin{array}{l}58 \\
58 \\
68 \\
56\end{array}$ & $\begin{array}{l}(2 \cdot 6) \\
(2 \cdot 4) \\
(5 \cdot 2) \\
(1 \cdot 3)\end{array}$ & $\begin{array}{l}42 \\
31 \\
30 \\
34\end{array}$ & $\begin{array}{r}(5 \cdot 3) \\
(4 \cdot 1) \\
(10 \cdot 8) \\
(13 \cdot 0)\end{array}$ & $\begin{array}{l}1426 \\
1349 \dagger \\
1239 t \\
1436\end{array}$ & $\begin{array}{l}(19.5) \\
(30.3) \\
(47 \cdot 5) \\
(71 \cdot 6)\end{array}$ & $\begin{array}{c}9 \cdot 2 \\
15 \cdot 2 \ddagger \\
19 \cdot 4^{\ddagger} \\
13 \cdot 4^{\ddagger}\end{array}$ & $\begin{array}{l}(1 \cdot 1) \\
(0 \cdot 9) \\
(1 \cdot 6) \\
(1 \cdot 3)\end{array}$ \\
\hline
\end{tabular}

*PICS = pericerebral space (see Harper et al, 1984).

$\dagger \quad=0.05>\mathrm{p}>0.02$.

$\pm \quad=0.01>\mathrm{p}>0.001$.

SEM = standard error of the mean.

Alco + WE $=$ alcoholic cases with Wernicke's encephalopathy

Alco + cir $=$ alcoholic cases with cirrhosis of the liver.

The fresh brain weight and volume were measured for each case at necropsy. The cerebellum and brainstem were removed by sectioning at the midbrain and the hemispheres were divided in the sagittal plane. The weight and volume of the left hemisphere and cerebellum were measured before and after being fixed in $10 \%$ buffered formyl saline for 14 days. The left hemisphere was subsequently sectioned at $3 \mathrm{~mm}$ intervals in the coronal plane according to the protocol described in our previous studies ${ }^{8}$ and morphometric quantitation of the volumes of cerebral cortex, white matter and diencephalic structures determined.

The right hemisphere was cut at three levels in the coronal plane: (1) frontal, immediately anterior to the temporal pole; (2) parietal, at the level of the central sulcus; (3) occipital, at the level of the parieto-occipital sulcus.

The sample blocks were taken from the anterior cut surface for the frontal and parietal lobes and from the posterior surface for the occipital lobe. The leptomeninges and ependyma were not included in any sample. Samples were taken from the deep white matter as differences in the water content have been noted between the deep and arcuate white matter. ${ }^{10}$

\section{Water content determination}

Samples, of approximately $1 \mathrm{~g}$, from the deep white matter of the frontal, parietal and occipital lobes were placed in pre-weighed $7 \mathrm{ml}$ bottles and re-weighed to determine the wet weight of the tissue. The specimens were then dried in a hot air oven at $100^{\circ} \mathrm{C}$ for 64 hours, to a constant weight, cooled in a desiccator for 30 minutes and re-weighed to determine the dry weight of the tissue. The percentage water was calculated according to the following equation:

$$
\% \text { water }=\frac{\text { wet weight }- \text { dry weight }}{\text { wet weight }} \times 100
$$

Statistical analyses were performed on an HP 11C calculator and included $t$ tests for two means and linear regressions.

\section{Results}

The alcoholic and control cases were age and sex matched (see table 1). The Wernicke's encephalopathy subgroup was older than the alcoholic and control populations.

The alcoholics were found to have a significantly reduced mean brain weight when compared to the controls. The pericerebral space (PICS) is a measure of the space between the brain and the skull and gives an accurate indication of brain shrinkage (or swelling).$^{7}$ As previously reported $^{2}$ the PICS was significantly increased in the alcoholics. The mean brain weight and PICS value of the cirrhotic group were not significantly different from the controls but the PICS value was $13.4 \%$ compared with the control value of $9 \cdot 2 \%$.

Table 2 shows the water content of the white matter of the frontal, parietal and occipital lobes and the

Table 2 Percentage water content in white matter for the control and alcoholic groups

\begin{tabular}{|c|c|c|c|c|c|c|c|c|}
\hline \multirow[b]{2}{*}{ Group } & \multicolumn{2}{|c|}{ Frontal } & \multicolumn{2}{|c|}{ Parietal } & \multicolumn{2}{|c|}{ Occipital } & \multicolumn{2}{|l|}{$t$} \\
\hline & Mean & $(\overline{S E M})$ & Mean & $(S E M)$ & Mean & $(S E M)$ & Mean & $(S E M)$ \\
\hline $\begin{array}{l}\text { Control } \\
\text { Alcoholics } \\
\text { Alco + WE } \\
\text { Alco + cir }\end{array}$ & $\begin{array}{l}70 \cdot 9 \\
72 \cdot 0 \\
73 \cdot 4^{*} \\
71 \cdot 4\end{array}$ & $\begin{array}{l}(0.3) \\
(0.5) \\
(1 \cdot 7) \\
(0.6)\end{array}$ & $\begin{array}{l}69 \cdot 8 \\
70 \cdot 4 \\
70 \cdot 5 \\
70 \cdot 8\end{array}$ & $\begin{array}{l}(0 \cdot 2) \\
(0 \cdot 3) \\
(1 \cdot 3) \\
(0.5)\end{array}$ & $\begin{array}{l}70 \cdot 4 \\
71 \cdot 2 \\
72 \cdot 3 \\
71 \cdot 8\end{array}$ & $\begin{array}{l}(0 \cdot 4) \\
(0 \cdot 24) \\
(1 \cdot 6) \\
(1 \cdot 2)\end{array}$ & $\begin{array}{l}70 \cdot 4 \\
71 \cdot 2 \\
72 \cdot 1 \\
71 \cdot 4\end{array}$ & $\begin{array}{l}(0.3) \\
(0.4) \\
(1 \cdot 5) \\
(0.8)\end{array}$ \\
\hline
\end{tabular}

$\begin{array}{ll}* & =0.02>\mathrm{p}>0.01 \\ \dagger & =\text { mean of frontal, parietal and occipital samples. } \\ \text { Alco }+\mathrm{WE} & =\text { alcoholic cases with Wernicke's encephalopathy. }\end{array}$

Alco + WE $=$ alcoholic cases with Wernicke's encephalopathy.

Alco + cir $=$ alcoholic cases with cirrhosis of the liver. 
mean for all three areas for the control and alcoholic groups. There is an increase in the water content of the white matter in the alcoholic cases in all areas; however, it is only significant in the frontal lobe of the Wernicke's encephalopathy group. The water content of the white matter was not significantly different in the subgroups of alcoholics (those with Wernicke's encephalopathy and cirrhosis) when compared with the alcoholic group as a whole.

Regression analyses were performed on both the control and alcoholic data. There was a significant increase in the mean water content of the white matter with increasing age in both the control and alcoholic groups (control; slope $=0.053, y=67 \cdot 3, p=0.01$ : alcoholic; slope $=0.082, y=66 \cdot 4, p=0.01$ ). However, the ages of the control and alcoholic groups are identical so that the age related changes could not account for the differences found.

No significant correlation was found between the postmortem interval and the water content. Similarly no significant correlation was found between the water content and the degree of shrinkage of the brain (PICS) in either the control or alcoholic groups.

\section{Discussion}

There is a significant increase in the water content of the frontal lobe white matter of alcoholics with Wernicke's encephalopathy. A similar consistent trend is seen in the parietal and occipital samples of the Wernicke's encephalopathy group and all samples from the total alcoholic group and the cirrhotics. Obviously such an increase in water content is inconsistent with the hypothesis that brain shrinkage in alcoholics is due to dehydration of the cerebral white matter. However, an increase in the water content of white matter may be indicative of other structural alterations. For example loss of myelin as seen in multiple sclerosis causes a relative increase in the water content because myelin contains less water than whole white matter. ${ }^{11}$ The fact that the change in water content appears to be greater in the frontal region is of interest in that neuropsychological, ${ }^{12}$ neuroradiological ${ }^{13}$ and neuropathological ${ }^{14}$ studies have emphasised frontal lobe damage and shrinkage in alcoholic patients.

Such a change in the water content of the white matter would be consistent with the potential reversibility of brain shrinkage following prolonged abstinence because loss of neurons from the cerebral cortex is indisputably irreversible whereas there is evidence to suggest that regenerative phenomena can occur in axons and myelin sheaths (that is, white matter) in the central nervous system. ${ }^{15} 16$

In vivo studies using magnetic resonance imaging (MRI) have found that the free water content of the cortex and white matter of alcoholics is decreased during intoxication, but it is increased after several days abstinence. ${ }^{17}$ Similarly when the total free brain water was examined at two stages of alcohol withdrawal it was found to be much higher than in the controls after 24 hours, but then decreased to be only slightly higher after 7-21 days withdrawal. ${ }^{18}$

The results of other brain water studies in alcoholics have been contradictory. Lesch et al ${ }^{19}$ reported a decrease in the water content of the white matter in alcoholic brains, whilst Shaw et al ${ }^{20}$ first reported an increase in the forebrain (including cortex and white matter) of alcoholics, but later ${ }^{21}$ reported no significant difference between alcoholics and controls. The mean water content for the controls of $70.4 \%$ corresponds well with previous reports. ${ }^{1120}$ It is of interest to note the increase in the water content of the white matter related to age. Other authors have noted a similar increase in the water content of whole brain specimens. ${ }^{22} 23$

This work was supported by grants from the Australian Associated Brewers, the New South Wales Drug and Alcohol Authority and the National Health and Medical Research Council (Grant No. 870564).

\section{References}

1 Carlen PL, Wilkinson DA, Wortzman G, et al. Cerebral atrophy and functional deficits in alcoholics without clinically apparent liver disease. Neurology 1981;31:377-85.

2 Harper C, Kril J. Brain atrophy in chronic alcoholic patients: a quantitative pathological study. J Neurol Neurosurg Psychiatry 1985;48:211-7.

3 Carlen PL, Wortzman G, Holgate RC, Wilkinson DA, Rankin JG. Reversible cerebral atrophy in recently abstinent chronic alcoholics measured by computer tomographic scans. Science 1978;200:1076-8.

4 Cala LA, Jones B, Mastaglia FL, Wiley B. Brain atrophy and intellectual impairment in heavy drinkers; a clinical, psychometric and computerized tomography study. Aust $N Z J \mathrm{Med}$ 1978;8:147-53.

5 Eisenhofer G, Johnson RH. Effects of ethanol ingestion on plasma vasopressin and water balance in humans. Am J Physiol 1982;242:522-7.

6 Harper CG, Blumbergs PC. Brain weights in alcoholics. J Neurol Neurosurg Psychiatry 1982;45:838-40.

7 Harper C, Kril J, Raven D, Jones N. Intracranial cavity volumes: a new method and its potential applications. Neuropathol Applied Neurobiol 1984;10:25-32.

8 Harper CG, Kril JJ, Holloway RL. Brain shrinkage in chronic alcoholics: a pathological study. Br Med J 1985;290:510-4.

9 Harper CG. Wernicke's Encephalopathy-a more common disease than realised. $J$ Neurol Neurosurg Psychiatry 1979;42:226-31

10 Adachi M, Feigin I. Cerebral oedema and the water content of normal white matter. $J$ Neurol Neurosurg Psychiatry 1966;29:446-50.

11 Davidson AN, Wajda $M$. Cerebral lipids in multiple sclerosis. $J$ Neurochem 1962;9:427-32.

12 Walsh KW. Alcohol related brain damage: an hypothesis. Aust Alc/Drug Rev 1983:2:1:84. 
13 Ron MA. The alcoholic brain: CT scan and psychological findings. Psychol Med 1983;momograph suppl No. 3:1-33.

14 Harper C, Kril J, Daly J. Are we drinking our neurones away? Brit Med J 1987;294:534-6.

15 Sumner BEH, Watson WE. Retraction and expansion of the dendritic tree of motor neurones of adult rats induced in vivo. Nature 1971;233:273-5.

16 Grafstein B, McQuarrie IG. Role of the nerve cell body in axonal regeneration. In: Cotman CW, ed. Neuronal Plasticity. New York: Raven Press, 1978:155-95.

17 Besson JAE, Glen AIM, Foreman EI, et al.Nuclear magnetic resonance observations in alcoholic cerebral disorder and the role of vasopressin. Lancet 1981;ii:923-4.

18 Smith MA, Chick J, Kean DM, et al. Brain water in chronic alcoholic patients measured by magnetic resonance imaging. Lancet 1985;:1273-4.
19 Lesch P, Schmidt E, Schmidt W. Effects of chronic alcohol abuse on the structural lipids in the human brain. Z Klin Chem Klin Biochem 1972;10:410-5.

20 Shaw DM, Camps FE, Robinson AE, Short R, White S. Electrolyte content of the brain in alcoholism. Br J Psychiatry 1970;116:185-93.

21 Shaw DM, Frizel D, Camps FE, White S. Brain electrolytes in depressive and alcoholic suicides. $B r \quad J$ Psychiatry 1969;115:69-79.

22 Davis JM, Himwich WA. Neurochemistry of the developing and aging mammalian brain. In: Ordy JM, Brizzee KR, eds. Neurobiology of Aging. New York: Plenum Press, 1975:329-57.

23 Samorajski T. Normal and Pathologic aging of the brain. In: Enna SJ, Samorajski T, Beer B, eds. Aging vol 17: Brain Neurotransmitters and Receptors in Aging and Age-related Disorders. New York: Raven Press, 1981:1-12. 